International Journal of Korean Humanities and Social Sciences

Vol. 4/2018

DOI: http://dx.doi.org/10.14746/kr.2018.04.05

\title{
THE REVIEW OF THE ROUTLEDGE COURSE IN KOREAN TRANSLATION BY JIEUN KIAER, 2018. ROUTLEDGE LONDON AND NEW YORK, ISBN 978-1-315-61821-0, PP. 197.
}

\author{
by Emilia WOJTASIK-DZIEKAN, PhD \\ Department of Korean Studies, \\ Institute of Linguistics \\ Adam Mickiewicz University \\ ewojtasik@yahoo.com
}

The Routledge Course in Korean Translation by Jieun Kiaer is a longawaited book that is supposed to fill the gap in the field of world translation literature, a book devoted to translation in the linguistic pair of English as a lingua franca and Korean as a language that is increasingly gaining world's attention. A specific goal the author adopted for the purposes of her book, which is "discuss[es] issues or problems that can occur in Korean-English (K-E) or EnglishKorean (E-K) translation" (Kiaer 2018: vi) and that it may serve as "a resource book for anyone engaged in Korean Studies" (2018: vii), indicates at the same time the potential areas of this book use in practice. The book is also intended to be a source of knowledge for scholars and adepts of Korean knowledge, and more broadly for all those who are interested in Asian languages.

The book consists of chapters devoted to matters, which is a clear signal of the author's awareness that translation is not just a thoughtless translation of the message but - on the contrary - that 
in the case of translation not only semantic transfer takes place, but other circumstances are taken into account. So everything matters, which is also a kind of word game.

The first chapter, entitled Language matters, introduces the reader to the world of Korean language, with the linguistic, morphological and syntactic differences of both languages (English and Korean) emphasized, which is preceded by the outline of the historical development of the Korean language. The author discusses the layout and structure of the alphabet, selected styles of Romanization record, also points to the areas of language influence of neighboring countries (China and Japan). Simultaneously, the author also makes simplified considerations on the aspects of Korean syntax and morphology and gives limited information about the development of English translation studies in Korea, as the text is aimed at people who speak English. One can see a comparative approach to the issues of Korean and English linguistics. An interesting solution is also the author's own comparative civic comments.

The next chapter is entitled Translating matters and is an introduction to translation studies. A globally functioning division of oral and written translation is introduced. This chapter should be treated as a specific state of research in translatology and equivalence, as it contains references to the findings of Jakobson (1959), Catford (1965), Baker (1992), Vermeer (1978) and Vermeer and Reiss (1984), Nida (1964) ), Newmark (1981) and others. It also contains selected translation techniques based on the Hasegawa proposal (2012) with a comment supported by examples in Korean. At the end of the chapter, there are several exercises that allow a reader to test one's translation skills. In the context of the entire book concept, particular attention should be addressed to the theoretical subchapter 2.3, which refers to the English-Korean cultural translation with an indication of the main problems in the translation of onomatopoeia, gender and numbers, names of drinks etc. This section is, in the opinion of the reviewer, particularly valuable.

Chapter 3 discusses the issues of grammatical differences in English and Korean, focusing on the issues of grammatical categories, number, genus, articles, particles and other grammatical exponents, times. It also raises the problem of understanding long and complicated sentences in both languages, pointing to the problem 
of syntax and connectivity of individual word groups. This chapter also ends with a set of exercises.

The chapter devoted to meaning indicates the problems of translation along with proposals for solving them with the examples of: Korean proper names (here, it is referred to literary translation, e.g. Leafie from The Hen Who Dreamed She Could Fly (Kiaer 2018: 76). Cases, showing the complexity of the translation problem, at the same time raise the issues of cognitive synonymy in translation (Cruse 1986), polysemy, homophony and homonymy in the EnglishKorean context. They also indicate the issue of hyperonymy and hyponymy in translations from these languages, as well as the shifts of meanings of particular words over the years. The chapter also focuses on the problem of translating idioms, proverbs and metaphors.

The fifth chapter is entirely intended to give a broad approach to vocabulary. The features of Korean vocabulary (share of lexical morphemes of Chinese origin, etc.), word-formation tendencies (from Sino-Korean to Anglo-Korean) and the perception of these words and phrases by Korean society are discussed. It is also an important aspect for a translator who has to choose the right term, also guided by its frequency.

The next chapter focuses on expressiveness and tone, which is an important element in oral translation and, in turn, often constitutes a language batch disregarded in translation considerations. All these elements of the language allow to soften or stiffen the statement, but also to avoid direct statements at someone's address in Korean culture and language. This requires in-depth knowledge of modality ranges and honorific endings functioning in Korean. This chapter also mentions the issues of lexical and grammatical integrity that seems to be quite difficult for an English reader to assimilate and distinguish. The mentioned tones and styles of speech mix somewhat in the chapter, however, this is another significant cultural issue. The choice of style of expression is also associated with the register, dialectics and sociolectics. Hence, in this chapter there is enough room for a short discussion of emoticons.

The seventh chapter deals with phonetic and phonological aspects of the spoken languages. This is especially important in the translation of poetry and literature as well as songs. Repeatability of syllables and text rhythms is quite a challenge.

The last chapter focuses on translation and cultural transfer. Numerous references to the theories of Sapir-Whorf and Wierzbicka 
(1992) allow the reader to understand the author's concept pointing to enormous difficulties that lurk for translators trying to deal with culture in translation. This type of translation always requires difficult decisions, ultimately leading to the realization of one's own language and cultural limits. Phrases and untranslatable words are also included, as well as namely the names of colors, emotions, relations, philosophical concepts, etc.

The book is enriched with annexes containing selected Korean alphabet writing romanization systems. All exercises that have been placed at the end of a given chapter also have a set of suggested answers. The bibliography in this issue includes 70 positions. The book ends with indexes of: people, selected dates and texts used.

In summary, this book is a good start for people who, on the one hand, know both languages well enough to do the translation (some exercises are quite difficult and can be a category of challenges). On the other hand, one can feel a bit unsatisfied due to the slightly limited information of research literature. The book is, in turn, very strongly enclosed with examples, which makes it useful.

Being aware that the publication is always a certain compromise between possibilities and desires, it can be said that this book meets the author's assumptions revealed at the beginning and that the readers are given the opportunity to broaden their knowledge in Korean translation matters.

\section{References}

Baker, Mona. 1992/2011. In Other Words: A Coursebook on Translation. London: Routledge.

Catford, John Cunnison. 1965. A Linguistic Theory of Tranlation. Oxford: Oxford University Press.

Cruse, D. Alan. 1986. Lexical Semantics. Cambridge: Cambridge University Press.

Hasegawa,Yoko. 2012. The Routledge Course in Japanese Translation. London: Routledge.

Hwang, Sun-mi. 2013. The Hen Who Dreamed She Could Fly. Trans. Kim Chi-yeong. Penguin Books. 
Jakobson, Roman. 1959/2000. On Linguistic Aspects of Translation. In The Translation Studies Reader, ed. Lawrence Venuti. Londond and New York: Routledge.

Kiaer Jieun. 2018. The Routledge Course in Korean Translation. London and New York: Routledge.

Newmark, Peter. 1981. Approaches to Translation. Oxford: Pergamon Press.

Nida, Eugene. 1964. Towards a Science of Translating. Leiden, The Netherlands: E.J.Brill.

Reiss, Katharina and Hans, Vermeer. 1984. Grundlegung Einer Allgemeinen Translationstheorie. Tübingen, Germany: M. Niemeyer.

Vermeer, Hans. J. 1978. Ein Rahmen für eine allgemeine Translationstheorie. Lebende Sprachen 23, pp. 99-102.

Wierzbicka, Anna. 1992. Semantics, Culture and Cognition: Universal Human Concepts in Culture-Specific Configurations. New York: Oxford University Press.

황선미 Hwang Seon-Mi. 2000. 마당을 나온 암탉 Madang-eul naon amtak. 서울:사계절출판사 Seoul: Sagyejeol Chulpansa. 